\title{
Effectiveness of Creative Pedagogy in Enhancing the Knowledge and Awareness on Bullying amongst Secondary School Students
}

\author{
Jamalsafri Saibon, Syed Mohamad Syed Abdullah \& Amelia Leong Chiew Har \\ School Educational Studies, 11800 Universiti Sains Malaysia, Pulau Pinang \\ Tel: 04-6533238, Fax: 04-6572907 \\ jamalsafri@usm.my
}

\begin{abstract}
Previous research found that there are a correlation between the level of knowledge on bullying behavior and the level of bullying. Therefore, the Program 2BS: I'm a Buddy not a Bully, has been planned and implemented with the aim to enhance the knowledge and awareness on bullying among students. In addition, the program aims to improve the awareness on the values of diversity. Creative and fun pedagogy has been used as an approach to achieve the objectives of this program. Within this program, elements from group counseling and basic counseling skills, such as active listening, asking question, interpretation and empathizing, are embedded with aim of helping counselors to explore bullying issues among students. A total of 500 students from different schools orientation (daily, academic, religious and sport) have been engaged in the experimental research. The results showed a significant increase in knowledge and awareness of bullying behavior among students who participate in this program. The findings from interviews found students are very excited and can better understand the content of which is carried out using this creative pedagogy approach. Also, this program helped them to appreciate the universal values and the diversity among students.
\end{abstract}

Keyword: Creative and Fun Pedagogy, bullying behavior, knowledge and awareness of bullying behavior, 2BS program.

\section{INTRODUCTION}

The issue of bullying among school children is a global phenomenon that is increasingly serious. According to Shakoor et. al. (2012), bullying is one of the major concern in the world where school children are bullied in school, which heeds for prevention and anti-bullying work in schools. In addition, Uba, Yaacob, Juhari and Talib (2010) added that bullying issues that occurs is not just hurting, even has reached a level of loss of life. This suggests that bullying behavior amongst students in school should not be taken lightly or regarded as a culture in school. As such, immediate action should be taken to prevent the bullying behavior from widespread among schoolchildren.

There are many factors contributing to the occurrence of bullying behavior, namely family dynamics (Hazler, 1996), parenting and family environment (Keenan, Evans \& Crowley, 2016), styles and characteristics of the family's parenting (Cummings, Davies, \& Campbell, 2000), peer social status (Jamalsafri, 2015), and role models (Olweus et al., 2007) school, teacher and class size (Rigby \& Smith, 2011R), and the school environment (Astor, Meyer and Behre, 1999). Besides the use of technology, media images and messages (Cherney and London 2006) and lastly the violent television shows and computer games, (Anderson \& Bushman, 2001). From these studies, it is clear that many researchers focus on family, school, peer group and the influence of mass media and technology as the cause of bullying behavior.

However, the lack of knowledge regarding bullying behavior amongst students not much discussed.
Literature indicates that there was a correlation between the level of knowledge on bullying behavior and the level of bullying amongst the students. This suggests that a student with less knowledge and awareness about bullying behavior, tend to be involved as a bully. Therefore, there should be a bullying prevention program in schools that emphasizes on the knowledge and awareness of bullying behavior.

There are several bullying prevention programs that have been implemented in several European countries. Olweus Bullying Prevention Program (OBPP) is a leading prevention program. The main goals of the OBPP are to reduce existing bullying problems among students at school, preventing development of new bullying problems, and more generally, achieve better peer relations at school (Olweus et al., 2007). In addition, many bullying prevention programs have been developed and implemented with various approaches. However, there are not many bullying prevention programs that emphasize the knowledge and awareness of bullying behavior among students.

The 2Bs Program: I'm a Buddy not a Bully is a bullying prevention program that emphasizes on improving the knowledge and awareness of bullying among students. The pilot study of this program was conducted in several schools in the northern states of Malaysia. This program has applied creative pedagogy approach to increase the knowledge and bullying awareness among students. This creative pedagogical approach is the core of this program in disseminating bullying behavior knowledge to school children. Selection of this approach is appropriate for secondary school students which is the target group for this program. As such, it is necessary to examine to what extent the creative pedagogical approach able to 
increase knowledge about the behavior of bullying among school children.

This study was designed to investigate whether a creative pedagogy approach which is applied in the $2 \mathrm{Bs}$ Program: I'm a Buddy not a Bully, being able to enhance the knowledge of bullying behavior among students. Also examined whether through the knowledge gained from this program could lead to their awareness of bullying behavior indirectly. The study also aims to get more in-depth information in identifying the features of the creative pedagogical approach that influences its effectiveness through interviews method.

\section{STUDY BACKGROUND}

\section{Knowledge on Bullying Behavior}

As bullying is not a new phenomenon in schools and one of the worrying issues among the teachers and students, it is crucial to educate and equipped both the teachers and learners alike with the knowledge on bullying behaviour. A student with high level of knowledge about bullying behavior should know and understand well in terms of bullying definitions, bullying concepts, characters in bullying, types of bullying behavior, ways to deal with bully, how to avoid being bullied, how to help bully victims, and the factors causing bullying behavior. With the knowledge, it will help the student from being involved as a bully in bullying incident indirectly.

The definition of bullying behavior refers to the situation when individuals or groups of people have more power, repeatedly and intentionally cause injury or danger to the people or groups of people who feel helpless to respond. Bullying may persist from time to time, often hidden from adults, and may persist if no action is taken. While the definition of bullying is broad and can occur in a variety of environments, it is usually a relationship problem and requires a relationship-based solution. In addition, bullying is behavioral related problem which impacted the lives of many families, mainly their children. Children who are bullied usually experienced fear, humiliation and frustration which consequently caused the children to be having low self-esteem, isolating themselves from their peers, absent from school, change in personality, mood swing, depression and worst of all, suicidal. Besides, Swearer and Hymel (2015) suggest that bullying "victimization is often characterized as a rather stable experience, but stability estimates vary as a function of time, age, and methodology".

There are many different types of bullying which experienced by both the children and adults alike. Some of these bullying are obvious to be identified while others are more subtle. The different types of bullying, namely are the physical bullying, verbal bullying, social bullying, and cyber bullying. Physical bullying includes hitting, kicking, tripping, pinching and pushing or damaging property. Physical bullying causes both short term and long term damage. Findings from researches showed that male is more involved, more aggressive and direct in bullying, hence, male has higher tendency in bullying the victim physically as compared to the female (Scheithauer et. al., 2006). Card, Stucky, Salawani and Little (2008) also stated that regardless of age group, ethnicity, social class, cultures or nationalities, boys are more likely to engage in physical bullying as compared to girls. Verbal bullying includes name calling, insults, teasing, intimidation, homophobic or racist remarks, or verbal abuse. While verbal bullying can start off harmless, it can escalate to levels which start affecting the individual target.

Social bullying, sometimes referred to as covert bullying, is often harder to recognize and can be carried out behind the bullied person's back. It is designed to harm someone's social reputation and/or cause humiliation. The victims would normally possessed very low self-esteem, feeling oneself not good enough or even depression when they face exclusion bullying (Boulton, Trueman, \& Murray, 2008). Cyber bullying can be overt or covert bullying behaviors using digital technologies, including hardware such as computers and smartphones, and software such as social media, instant messaging, texts, websites and other online platforms. Cyber bullying can happen at any time. It can be in public or in private and sometimes only known to the target and the person bullying.

The knowledge of bullying behavior benefits many students when they face bullying situations in school. This knowledge will help them to make decisions when they are in a situation as a bystander who is watching bullying and help them avoid being bullied when dealing with bully. As such, it is anticipated that students with high level of bullying behavior have a tendency to not bully and otherwise students with low level of bullying will tend to bully other students.

\section{Creative and Fun Pedagogy}

This pedagogy is introduced by Andrei Aleinikov, (1989) which the main idea is if teachers transform their class-rooms into creative learning environments, this will be better to promote lifelong learning. If pedagogy in general is defined as the study of the process of teaching, then creative pedagogy is defined as the science and art of creative teaching (Aleinikov, 1990). Creative pedagogy is a branch of pedagogy that emphasizes the leading role of creativity for successful learning. In its essence, creative pedagogy teaches learners on how to learn creatively and become the creators of themselves and the creators of their future.

There are various definitions related to creative pedagogy. Creative pedagogy is seen to involve teachers in making learning more interesting and effective and using imaginative approaches in the classroom (Cremin, T, Burnard, P \& Craft, A (2006). In order to implement creative pedagogy, the teacher needs to widen their understanding of their own creativity, imaginative approaches and repertoire of engaging activities that they can employ in developing the children's capacity for original ideas and action.

Creativity requires new way of thinking, acceptance of something uncertain and the willingness 
to accept failure. It is important to provide an environment which is conducive to provide the students with courage through learning new experiences. For example, if the students feel valued, their confidence and independence level will increase and they will begin to take responsibility of their own learning. Teacher and student relationships are important in contributing in this development. Teachers play important role as facilitators to encourage active and flexible participation from students and in turn make the teaching process a creative learning process (Dineen \& Niu, 2008).

Creative pedagogy is an art which can helps the learners to learn creatively with transforming the conventional classroom into a creative learning environment. Through this pedagogy, it allows the learners to innovate, create, and take risks and to think imaginatively. Role of the learner in creative pedagogy acts as an object of influence the learners. The learners' status is raised to be one of creative person (Joubert, 2001).

According to Dineen and Niu (2008), the creative pedagogical models are able to enhance the creativity, the level of confidence and the intrinsic motivation of the students. The classroom needs to transform to be a flexible learning environment. The four components of creative pedagogy: 1) Fluency-generating new ideas. 2) Flexibility-shifting perspectives. 3) Originalitydoing something new. 4) Elaboration-building on existing ideas. According to Lin (2011), creative pedagogy using an imaginative approach can make learning more interesting and effective. In addition, creative pedagogy is able to identify students' abilities and at the same time, is able to encourage and provide opportunities for their capacity development.

Creative pedagogy emphasizes the role of teachers and the students. In addition, the example of creative teaching pedagogy, is conducted by using the imagination, dynamic and innovative approaches and new ideas that lead to the creative pedagogy. In addition, creative pedagogy can also encourage student engagement in learning, explore new things, and then strive to be creative in order to raise curiosity and increase students' motivation in learning (Lin, 2011). Hence, the use of this creative pedagogical approach is one of the ways to disseminate knowledge to students creatively. As such, it is anticipated that by applying this creative pedagogy to bullying behavior prevention programs is able to enhance student knowledge about bullying behavior amongst students.

\section{What is 2 Bs Program?}

The $2 \mathrm{Bs}$ represent the two words that start with the letter B, namely bully and buddy. This programme has been planned and implemented based on research which found out that the level of knowledge on bullying among students is at a low level. This study also found out that the there is a negative significant correlation of the levels of knowledge on bullying with the level of bullying.

Thus, in 2010, the 2Bs programme: 'I'm a Buddy, not a Bully' was developed and designed to enhance knowledge on bullying behaviour and to nurture awareness among school students. The program is funded by the Division of Industry and Community Network, University Sains Malaysia (USM) and The School of Educational Studies, USM has extended their support throughout this programme. The State Educational Department of Penang, the schools and the respondents of the survey also gave their unwavering support.

The 2Bs programme was implemented in three major phases. The first phase aims to enhance knowledge and to create awareness of bullying problems among the students through creative pedagogy approaches and the execution of the 'I'm a Buddy, Not a Bully' campaign. The concepts underlying the first phase involve the extensive use of creative and fun pedagogical approach, which was introduced by Dr. Andrei Aleinikov.

The first phase uses a system of four stations that has its own specific theme related to bullying. This approach will equip the target groups with the knowledge, awareness and actions to be taken when dealing with bullying situations. The creative and fun pedagogical approach includes utilizing the elements of art such as music, sculpting, poetry, acting, dancing, paper collaging, and puppetry under the theme of bullying. This was presented and guided by facilitators, counsellors and teachers who had undergone training.

By using a creative and fun pedagogical approach, the programme was able to draw active support from the participants. This kind of approach helps the students to understand and prepare them to handle unpleasant bullying situation. This is different from the classroom teaching style, which only provides a theoretically based situation but this approach combines both the class lectures and practical application. The 2Bs programme: "I'm a Buddy not a Bully" has received the EIU Best Practices Award 2013, organized by the Asia Pacific Center of Education International Understanding (APCEIU) under UNESCO, South Korea.

\section{METHODOLOGY}

This study employs a quantitative method with the support of qualitative approaches. Quasi experiments design which randomly assigns whole classes to treatment and control (Campbell and Stanley, 1963) was used to examine the effectiveness of pedagogical creative approaches in increasing bullying knowledge and awareness among the school children. Meanwhile, an interview has also been conducted on five students to obtain a deeper understanding of the effectiveness of this creative pedagogy. A total of 234 pupils were randomly selected as sample samples. The sample consists of 130 male students and 104 female students aged between 14 to 16 years old. They were selected from five different oriented schools in the state of Penang. The schools are proposed by the Penang State Education Department which consisted of two secondary schools, religious schools, high-performing schools and sports schools. 
In this quasi experiment, students have undergone pre-tests and post-tests. The Student Bullying Knowledge Level (TPBL) questionnaire was administered to the samples before and after the 2Bs Program was implemented. This questionnaire contains 25 items which examine the student knowledge about bullying behavior. The TPBL questionnaire has undergone validity and reliability processes conducted before the study. Structured interviews were conducted on seven randomly chosen students who had participated in the program.

Before undergoing a 2Bs Program that applied a creative pedagogical approach, the sample responded to the Student Bullying Knowledge Level (TPBL) questionnaire. After the program they were asked to attempt the questionnaire again. To measure the effectiveness of the creative pedagogical approach in enhancing the knowledge and bullying awareness among the school students, a T-test analysis was performed to obtain statistical data. Meanwhile, the interview data was analyzed utilizing the thematic method.

\section{RESULTS}

This study was designed to test a hypotheses: there is a significant difference between pre-test scores and post-test scores on bullying behavior knowledge amongst students who are participated in the 2Bs Programme that apply the creative pedagogical approach. Findings from the pre-test questionnaires (table 1) showed that the mean score of the students on knowledge and awareness of bullying is in the moderate level (Mean=49.66). After undergoing the 2Bs program, the students' mean score of the post-tests questionnaires increased to the moderate high level (Mean=72.77). This shows that there has been a significant increase in student knowledge scores on bullying behavior between pretest and post-test scores.

Table 1: Paired Samples Statistics

\begin{tabular}{|c|c|c|c|c|c|}
\hline & & Mean & & $\begin{array}{l}\text { Std. } \\
\text { Deviation }\end{array}$ & $\begin{array}{l}\text { Std. } \\
\text { Error } \\
\text { Mean }\end{array}$ \\
\hline \multirow{2}{*}{ Pair 1} & Test1 & 49.66 & 234 & 13.57 & 1.249 \\
\hline & Test 2 & 72.77 & 234 & 9.73 & .896 \\
\hline
\end{tabular}

This finding clearly shows that creative pedagogy applied in 2BS Program: 'I'm a Buddy not a Bully' has managed to improve achievement scores in knowledge about bullying among students who have participated in this program. Analysis from Paired Samples Correlations showed (table 2) that there is a significant correlation between the pre-test and the posttest $(\mathrm{p}<.001)$. These findings indicated that the enhancement of knowledge and awareness on bullying which involved all the participants in the study.
Table 2: Paired Samples Correlations

\begin{tabular}{ll|lll} 
& & N & Correlation & Sig. \\
\hline Pair 1 & $\begin{array}{l}\text { Test1 \& } \\
\text { Test 2 }\end{array}$ & & & \\
& & 34 & .567 & 000 \\
& & & \\
\hline
\end{tabular}

Experimental methods were used to evaluate the effectiveness of the programme. The statistic results of the T-test below showed that there is a significant difference $(\mathrm{t}=-22.106, \mathrm{df}=233, \mathrm{p}>.01)$. The test results showed that the $2 \mathrm{Bs}$ programme has influenced the performance of students to answer the questions related to knowledge of bullying and awareness on the diversity among peers. The difference in the mean score value for both the tests is large. These findings indicated that this creative pedagogy used in 2Bs programme managed to increase knowledge and awareness of bullying among students who live in school hostel.

Table 3: Paired Samples Test

\begin{tabular}{|c|c|c|c|c|c|c|c|c|}
\hline & & I & ired Di & erences & & & & \\
\hline & & & & $95 \%$ & & & & \\
\hline & & & & Confid & & & & \\
\hline & & & & ence & & & & \\
\hline & & & & Interv & & & & \\
\hline & & & & al of & & & & \\
\hline & & & & the & & & & \\
\hline & & & & Differ & & & & \\
\hline & & Std & & ence & & & & \\
\hline & & $\cdot$ & Std.E & & & & Sig. & \\
\hline & & $\mathrm{De}$ & rror & & & & $(2-$ & \\
\hline & & viat & Mea & Low & & & tailed & \\
\hline & Mean & ion & $\mathrm{n}$ & er & Upper & $\operatorname{tdf}$ & ) & \\
\hline Pair 1 & & & & & & & & \\
\hline Test1 & - & 11. & 104 & & & - & & $0 \Omega 0$ \\
\hline- & 23.11 & 36 & 1.04 & $\begin{array}{l}25.1 \\
8\end{array}$ & -21.04 & 22.10 & 233 & .000 \\
\hline Test 2 & & & & & & & & \\
\hline
\end{tabular}

The interview findings have found that students are so excited to follow the $2 \mathrm{Bs}$ program that apply the creative pedagogical approach. Fun and simulated factors through creative activities that have been planned have given them an understanding and real picture of bullying behavior. In addition they can also feel what is perceived by the bully, bullied and the bystander through acting and expression of feelings activities. In addition, they also suggest that creative pedagogy activities train them to look at the issue of bullying from a diverse perspective and make them better understand about bullying behavior.

\section{DISCUSSION}

The findings of the study have shown that the creative pedagogical approach is very effective in improving student knowledge about bullying behavior. This is evidenced by post-test scores on knowledge about bullying have increased significantly when they undergo treatment in the form of $2 \mathrm{Bs}$ programme that apply the creative pedagogical approach. Therefore, this study suggests that creative pedagogical 
approaches are an appropriate method for delivering learning content to students. This finding also supports some of Sivan et.al's (1991) study showcasing better learning outcomes and enhancing learning (Benjelloun, H. 2009), producing more effective learning (Robinson, CF, \& Kakela, PJ, 2006) able to increase curiosity (Lin, 2011), and achieve better results in learning (Toivanen, T., Halkilahti, L., \& Ruismäki, H., 2013).

This may be due to the characteristics of learning through creative pedagogical approach which was a significant increase students' knowledge about bullying behavior. From the literature found that creative pedagogy provides the elements of positive learning combining elements of excitement in the classroom and engaging actively and truly enjoying the learning process (Tews, MJ, Jackson, K., Ramsay, C., \& Michel, JW, 2015 ), have elements, games and simulations (Sivan et al., 1991), able to improve memory, imagination, creativity, potential, student grades and communication quality among pupils and teachers and further reduce the pressure faced by them (Benjelloun, H. 2009), and creative pedagogy can enhance creativity, confidence and student intrinsic motivation (Dineen, R., \& Niu, W. 2008). This clearly demonstrates that the positive learning elements contained in this creative pedagogy become the catalyst for a significant increase in student knowledge about bullying behavior. Indirectly, through acquired knowledge will create their awareness of bullying behavior.

The creative pedagogy also demonstrates that through creative activities it is able to solve a serious issue such as bullying issues in a way that the student receives more indirectly. In school bullying cases that occur normally are often solved with punishments that will negatively affect to the bully. While most bullying prevention programs in schools are often carried out in the form of tedious lectures. It is stated by a student who has been interviewed. On the other hand, this student is very interested in the creative pedagogical approach applied in this $2 \mathrm{Bs}$ Program which attracts the attention and focus of the students to be active in every activity they have undertaken. As such, creative pedagogy has provided an alternative in implementing bullying prevention programs which are oriented towards enhancing knowledge and awareness on bullying amongst students in schools.

\section{CONCLUSION}

The creative pedagogy approach has successfully enhanced the students' knowledge and awareness on bullying among students. Hence, the use of creative pedagogical approaches should be considered when planning and implementing a bullying prevention program that focuses on improving the knowledge of bullying behavior among school children. The knowledge of bullying obtained through this approach will create student awareness about bullying behavior and indirectly bullying issues will be addressed. Therefore, it is clear that any bullying prevention program should emphasize to increase the knowledge about bullying among students. This is to prevent misconceptions about bullying behavior that causes bullying in schools.

In addition, interviews and comments of the students involved found that they have acquired a lot of new knowledge about bullying and also has been successful in creating awareness on the bullying behaviour to them. The 2Bs Programme: 'I'm a Buddy, not a Bully, has been awarded as the EIU Best Practices 2013 by Asia-Pacific Centre of Education for International Understanding (APCEIU), Republic of Korea, under the auspices of UNESCO. This success has shown that international recognition of the effectiveness of creative pedagogy used in the program has increased the knowledge about bullying among students. It is hoped that the knowledge gained from the 2Bs programme which applies the creative pedagogical approach will help reduce bullying cases in school.

\section{BIBLIOGRAGPHY}

Aleinikov AG. Creative pedagogy and creative metapedagogy. Progress in Educ. 1990; 65(12):274-80.

Aleinikov AG. Creative metapedagogy: D-day. AlmaMater. Higher Educ Bull. 1989; 1: 34-9.

Anderson, C. A., \& Bushman, B. J. (2001). Effects of violent video games on aggressive behavior, aggressive cognition, aggressive affect, physiological arousal, and prosocial behavior: A meta-analytic review of the scientific literature. Psychological Science, 12, 353- 359

Astor, R. A., Meyer, H. A., \& Behre, W. J. (1999). Unowned places and times: Maps and interviews about violence in high schools. American Educational Research Journal, 36, 3-42

Benjelloun, H. (2009). An empirical investigation of the use of humour in university classrooms. Education, Business and Society: Contemporary Middle Eastern Issues, 2(4), 312-322.

Boulton M. J., Trueman M., Murray L. (2008). Associations between peer victimisation, fear of future victimisation and disrupted concentration on class work among junior school pupils. British Journal of Educational Psychology, 78, 473-489.

Campbell. D, T., \& Stanley. J. C. (1963). Experimental and Quasi-Experiment Designs For Research. Houghton Mifflin Company, Usa.

Card NA, Stucky BD, Sawalani GM, Little TD. Direct and indirect aggression during childhood and adolescence: A meta- analytic review of gender differences, inter correlations, and relations to maladjustment. Child Dev. 2008; 79(5):1185-229. doi: 10.1111/j.1467-8624.2008.01184.x

Cherney, I.D. \& London, K. Sex Roles (2006) 54: 717. https://doi.org/10.1007/s11199-006-9037-8

Cremin, T, Burnard, P and Craft, A (2006) Pedagogies of possibility thinking. International Journal of Thinking Skills and Creativity, 1:2, 108-19.

Cremin, T (2006) Creativity, uncertainty and discomfort: teachers as writers. Cambridge Journal of Education, $36: 3,415-33$.

Cummings, E.M., Davies, P.T., \& Campbell, S.B. (2000). Developmental Psychopathology and Family Process. New York: The Guilford Press.

Dineen, R., \& Niu, W. (2008). The effectiveness of western creative teaching methods in China: An Action 
research project. Psychology of Aesthetics, Creativity, and the Arts, 2(1), 42-52. http://dx.doi. org/10.1037/1931-3896.2.1.42

Hazler, R. J. (1996). Breaking the Cycle of Violence: Interventions for Bullying and Victimization. Washington, DC: Accelerated Development.

Jamalsafri Saibon (2015), The Relationship between Student's Statuses with Bully Behavior, Malaysian Education Deans' Council (MEDC) Journal Vol. 5, Penang: UPPA Press. (In Malay Language).

Joubert, MM (2001). The art of creative teaching: NACCCE and beyond, in Craft, A, Jeffrey, Keenan, T., Evans, S. \& Crowley, K. (2016). An Introduction to Child Development (third edition). London: Sage.

Liebling, M (eds) Creativity in education, London: Continuum

Lin, H. (2011): Three Principles of Soil Change and Pedogenesis in Time and Space. Soil Science Society of America Journal, 75(6):2049-2070. DOI: 10.2136/sssaj2011.0130

Olweus, D. (2007). Olweus Bullying Questionnaire: Schnabel paper version. Center City, MN: Hazelden.

Olweus, D., \& Limber, S. P. (2007). Olweus Bullying Prevention Program Teacher Guide. Center City, MN: Hazelden

Rigby, K., \& Smith, P. K. (2011). Is school bullying really on the rise? Social Psychology of Education, 14, 441-455

Robinson, C.F. and Kakela, P.J. (2006). Creating a space to learn: A classroom of fun, interaction, and trust. College Teaching, 54(1) 202-206. Retrieved fulltext from Wilson Web Education Full-Text, April 10, 2006.

Sania, S., Jaffee, S. R., Bowes, L., Ouellet-Morin, I., Andreou, P., Happé, F., \& Arseneault, L. (2012). A prospective longitudinal study of children's theory of mind and adolescent involvement in bullying. Journal of Child Psychology and Psychiatry, and Allied Disciplines, 53(3), 254261. http://doi.org/10.1111/j.14697610.2011.02488.x

Scheithauer, H., Hayer, T., Petermann, F., \& Jugert, G. (2006). Physical, verbal and relational forms of bullying among students from Germany: Gender-, age-differences and correlates. Aggressive Behavior, 32, 261-275.

Sivan, A., Leung, R. W., Gow, L., \& Kember, D. (1991).

Towards more active learning in hospitality studies. International Journal of Hospitality Management, 10, 369-379.

Swearer, S. \& Hymel, S. (2015). Bullying and Discrimination in Schools: Exploring Variations across Student Subgroups. School Psychology Review: December 2015, Vol. 44, No. 4, pp. 504-509.

Tews, M. J., Jackson, K., Ramsay, C., \& Michel, J. W. (2015). Fun in the college classroom: Examining its nature and relationship with student engagement. College Teaching, 63(1), 16-26.

T. Toivanen, L. Halkilahti, H. Ruismäki. (2013). Creative pedagogy - Supporting children's creativity through drama. The European Journal of Social \& Behavioural Sciences. 7, pp. 1168-1179.

Uba, I., Yaacob, S. N., Juhari, R., \& Talib, M. A. (2010, December). Effect of self-esteem on the relationship between depression and bullying among teenagers in Malaysia. Asian Social Science, 6(12), 77-85. 
